\title{
batillot
}

\section{A incoveniência dos TACs eleitorais}

José Luís Blaszak (Centro Universitário de Brasília, Brasil)

joseluis@blazak.adv.br

Universidade de Cuiabá, Campus Beira-rio, Faculdade de Direito.

Av. Beira Rio, 3100, Jardim Europa, 78015-480 - Cuiaba, MT - Brasil 


\title{
Resumo
}

Os Termos de Ajustamento de Condutas Eleitorais têm sido utilizados como instrumentos coercitivos nas eleições brasileiras, especialmente no tocante à propaganda. Após um tempo razoável de utilização destes instrumentos é momento de refletir a sua aplicabilidade. A presença dos TACs Eleitorais passou a ser um fator inibidor das manifestaçôes políticas por parte dos candidatos, coligações, partidos, cabos eleitorais, simpatizantes e pelo eleitor. A argumentação de que a população não suportava mais as práticas de propaganda eleitorais não legitima o nascimento de um instrumento sem previsão legal eleitoral e coercitivo.

Palavras-chave: Democracia; Legalidade; Propaganda Eleitoral

\section{The drawbacks of electoral consent decrees}

\begin{abstract}
Consent decrees (termos de ajustamento de condutas - TACs, or "terms to adjust conduct") are increasingly being used in electoral matters in Brazil, especially with respect to campaign propaganda. After a reasonable period of using these instruments, it is time to reflect on their applicability. The presence of electoral TACs has become a factor that inhibits political manifestations by candidates, parties, coalitions, canvassers, sympathizers and voters themselves. The argumentation that voters are fed up with electoral propaganda cannot be used to support a coercive mechanism without support in electoral law.
\end{abstract}

Keywords¥ Democracy; Legality; Electoral Propaganda 
Os Termos de Ajustamento de Condutas Eleitorais têm sido utilizados como instrumentos coercitivos nas eleições brasileiras, especialmente no tocante à propaganda. Após um tempo razoável de utilização destes instrumentos é momento de refletir a sua aplicabilidade.

Inicialmente, é de suma importância rememorar que as eleições diretas no nosso país foram conquistadas a "ferro e fogo", emprestando a expressão do autor gaúcho Érico Veríssimo. Não foi nada fácil. Não precisamos resgatar as minúcias desta conquista, pois são de amplo conhecimento. Quem viveu, comemora até hoje.

É do verbo "comemorar" que as eleições diretas no nosso país têm sua raiz e, por consequência devem ser um evento de alta propagação, revestidas de simbologia, de liturgia festiva e popular, indutivas à democracia. Seus propósitos estão longe de ser um conjunto de manifestações calculistas, frias, distantes da participação geral, restritas às cartilhas, de compromissos sob Termos de Ajustamento de Condutas.

Em 1997 o legislador pátrio, examinando o Código Eleitoral de 1965, percebeu que o código estava deveras afastado da contextualização eleitoral. Cunhou-se, então, a Lei das Eleições - Lei no 9.504/1997. Dentre outros temas, nela se fixou o regramento da propaganda eleitoral. Adicionado ao regramento da Lei das Eleições, o TSE passou a editar as resoluções para cada tema e a cada eleição. Deve-se considerar, ainda, o período das leis temporárias, vigentes antes da Lei ${ }^{\circ}$ 9.504/97, que vigiam apenas para cada pleito.

Precede às eleições um período de ampla discussão, de propagação de propostas, de embates de ideias, de demonstração de eloquência dos seus interlocutores, enfim, de uma ampla plataforma de campanha eleitoral. Campanha eleitoral significa colocar nas ruas todas as estratégias criadas nos comitês eleitorais, incluindo propostas e material de divulgação. A legislação permite a propaganda eleitoral de forma ampla por meio de abordagens formais, das mídias de propaganda e de marketing político. É dar sentido verdadeiro ao termo propaganda na seara eleitoral. Isso tudo, a fim de que o eleitor avalie um a um os candidatos, para depois, na urna, votar naquele que lhe pareça a melhor opção. Isso se concretizou por alguns anos.

Porém, nas eleições municipais de 2008, ou seja, somente onze anos após o advento da Lei das Eleiçóes, surgiu por iniciativa do Ministério Público Eleitoral um instrumento coercitivo para alterar substancialmente a prática da propaganda eleitoral, qual seja, o Termo de Ajustamento de Conduta Eleitoral.

A título de exemplificação, para comprovar o quanto os Termos de Ajustamento de Condutas são restritivos, vê-se o que está estampado no site da Procuradoria Regional Eleitoral do Paraná, em relação às eleições municipais de 2012:

"MP, Justiça e partidos firmam TAC para evitar abusos durante a campanha eleitoral em Guaíra

A Promotoria de Justiça em Guaíra (região Oeste do Paraná), o Juízo da Comarca e os partidos e coligaçóes no município firmaram Termo de Ajustamento de Conduta (TAC), nesta quinta-feira (26 de julho), para definir os limites da propaganda durante o período eleitoral.

A representante do MP-PR no TAC é a promotora de Justiça Silvia Leme Corrêa. O acordo vai vigorar durante toda a campanha e contempla a proibição de pintura em muros, fachadas ou portões de imóveis particulares (mesmo que o proprietário autori- 
ze), além de vedar a propaganda em placas, faixas, cavaletes, bandeiras e similares nas vias públicas. Também ficam proibidas as carreatas e passeatas no município.

Por outro lado, o TAC permite a realização de propaganda em carros de som, mas apenas no período entre $15 \mathrm{~h}$ e $20 \mathrm{~h}$.

Em relação à propaganda na véspera das eleições, o acordo estabelece que as coligações terão que fazer a entrega do material não utilizado na campanha entre $17 \mathrm{~h}$ e $18 \mathrm{~h}$ do dia 6 de outubro, na sede do Fórum Eleitoral.

As coligações também se comprometem a não veicular propaganda eleitoral por meio de impressos (santinhos, panfletos, jornais e similares) no dia da eleição ( 7 de outubro).

A desobediência implicará em multa de $\mathrm{R} \$ 5$ mil, valor a ser revertido em favor do Fundo de Meio Ambiente." 388

Destaca-se da nota:

"O acordo vai vigorar durante toda a campanha e contempla a proibição de pintura em muros, fachadas ou portóes de imóveis particulares (mesmo que o proprietário autorize), além de vedar a propaganda em placas, faixas, cavaletes, bandeiras e similares nas vias públicas. Também ficam proibidas as carreatas e passeatas no município." ${ }^{389}$.

É conclusivo que praticamente nada pode ser feito em termos de propaganda eleitoral a partir da aceitação deste TAC. Frisa-se, em muitos estados da federação tem sido utilizado deste modelo de conteúdo de TACs.

Além da lembrança ditatorial, uma vez que é imposto aos candidatos de forma unilateral, constrangedora, retrocedendo aos tempos de controle, tal instrumento se mostra totalmente anômalo, pois sua aplicabilidade acontece antes mesmo de quaisquer irregularidades praticadas. Não há lei alguma de cunho eleitoral com previsão de tal instrumento.

A inspiração dos TACs pode ser obtida no site do Conselho Nacional do Ministério Público CNMP que lá estampa: "O termo de ajustamento de conduta é um acordo que o Ministério Público celebra com o violador de determinado direito coletivo. Este instrumento tem a finalidade de impedir a continuidade da situação de ilegalidade, reparar o dano ao direito coletivo e evitar a ação judicial."390. (nosso grifo)

O CNMP aborda os termos de ajustamento sob a ótica da violação, de impedir a continuidade de situação de ilegalidade, enquanto no direito eleitoral nada disso é realidade. A aplicabilidade dos TACs eleitorais não pressupõe uma conduta irregular, ilícita. A incongruência está no fato de que na esfera eleitoral os termos são realizados antes de qualquer conduta ser praticada. Então, a lógica induz ao pensamento de que se não há conduta violadora não há que se falar em termos de ajustamento de conduta.

388. http://www.prepr.mpf.gov.br/noticias/mp-justica-e-partidos-firmam-tac-para-evitar-abusos-durantea-campanha-eleitoral-em-guaira

389. idem

390. http:/ www.cnmp.gov.br/direitoscoletivos/index.php/4-o-que-e-o-termo-de-ajustamento-de-conduta 


\section{Diz ainda o CNMP:}

"O termo de ajustamento de conduta está previsto no $₫ 6^{\circ}$ do art. $5^{\circ}$ da Lei 7347/85 e no art. 14 da Recomendação do CNMP n” 16/10:

Lei $n^{\circ} 7.347 / 85, \S 6^{\circ}$ - Os órgãos públicos legitimados poderão tomar dos interessados compromisso de ajustamento de sua conduta às exigências legais, mediante cominações, que terá eficácia de título executivo extrajudicial.

Recomendação do CNMP nº 16/10, art. 14 - O Ministério Público poderá firmar compromisso de ajustamento de conduta, nos casos previstos em lei, com o responsável pela ameaça ou lesão aos interesses ou direitos mencionados no artigo $1^{\circ}$ desta Resolução, visando à reparação do dano, à adequação da conduta às exigências legais ou normativas e, ainda, à compensação e/ou à indenização pelos danos que não possam ser recuperados." ${ }^{391}$ (grifo nosso)

Destaca-se, que o próprio CNMP recomenda a necessidade de previsão legal para a utilização de termos de ajustamento. Fica claro e evidente que a manifestação do CNMP diz respeito à lei das açóes civis públicas. Portanto, sem nenhuma relação com o direito eleitoral, uma vez que não há previsão de ação civil pública no ordenamento eleitoral.

O Desembargador LEONEL CARLOS DA COSTA do Tribunal de Justiça do Estado de São Paulo, em artigo, alerta sobre os limites da aplicação dos TACs, levando o leitor eleitoralista a concluir que não há elementos suficientes para autorizar a sua prática nesta seara.

"Mas até que ponto esses TACs podem ser feitos e penetrar no campo da liberdade individual, de trabalho, do exercício livre da atividade econômica ou da liberdade de pensamento e direito autoral?

Em sua atuação constitucional positiva de defesa da ordem jurídica e dos interesses sociais e individuais indisponíveis (art. 127 da CF), a instituição do Ministério Público tem se utilizado do Termo de Ajuste de Conduta como instrumento efetivo dessa missão constitucional com muita frequência, normalmente no contexto de um inquérito civil (art. 129, III da CF), mas que não deve desbordar dessa função teleológica primária que a Constituição Federal lhe cobra, evitando o risco de ilegalidade ou abuso a serem identificados eventualmente no controle jurisdicional.

O instrumento jurídico do Compromisso de Ajustamento de Conduta, também conhecido como Termo de Ajuste de Conduta (TAC), foi primeiramente criado pelo art. 211 do Estatuto da Criança e do Adolescente - ECA (Lei n. 8.069/90) [1] e, depois, pelo art. 113 do Código de Defesa do Consumidor - CDC (Lei n. 8.078/90), que acrescentou o $\S 6^{\circ}$ ao art. $5^{\circ}$ da Lei da Ação Civil Pública (Lei n. 7.347/85)[2]

Por meio dele, o órgão público legitimado à ação civil pública toma do causador do dano - ainda quem em potencial - a interesses difusos, interesses coletivos ou interes-

391. idem 
ses individuais homogêneos o compromisso de adequar sua conduta às exigências da lei, mediante cominações, que têm o caráter de título executivo extrajudicial." 392

Diz ainda o desembargador, afirmando a necessidade de previsão legal para a adoção de TACs:

"Mas o chamado TAC- Termo de Ajustamento de Conduta é meio excepcional de transação, somente cabível nos casos expressamente autorizados pela lei, com o intuito de permitir ao potencial agressor de direitos difusos, coletivos ou transindividuais de atender e se adequar ao interesse tutelado, tão somente em situaçóes de nebuloso desenho normativo ou que demande contornos a serem melhor definidos.

Com certeza, não é raro que existam casos em que nem sempre a legislação tem a completa previsibilidade de todos os pormenores e da dinâmica própria das práticas comerciais ou contratuais relativas aos interesses difusos e ou coletivos, difíceis na maioria das vezes de manejo na sua tutela judicial e complexa ou quase impossível de efetivação.

Assim, não é meio adequado o TAC para dar solução já claramente definida e regulada de forma exauriente pela normatividade positiva, nem se presta a alforriar o infrator da lei às sanções por ela cominadas, não se prestando como meio de atuação política, perseguição ou de favorecimento, não se devendo abrir espaço para conjecturas que coloquem em dúvida os ilibados motivos e fins determinantes de sua proposta." 393

O professor HUGO NIGRO MAZZILLI chama a atenção em artigo que os TACs somente podem ser realizados por órgãos legitimados à ação civil pública ou coletiva.

"Só podem tomar o compromisso de ajustamento de conduta os órgãos públicos legitimados à ação civil pública ou coletiva.

Isso significa que não são todos os legitimados à ação civil pública ou coletiva que podem tomar compromisso de ajustamento, mas só aqueles que somam à sua condição de legitimados ativos a condição de órgãos públicos." ${ }^{394}$

Isso significa que os TACs não são instrumentos apropriados para a seara eleitoral, uma vez ausente nela a previsão legal de ação civil pública. O Ministério Público Eleitoral não pode emprestar da lei de ação civil pública a legalidade dos TACs.

O professor HUGO NIGRO MAZZILLI aborda ainda a natureza jurídica dos TACs o que corrobora com a tese da inadequação dos TAC na seara eleitoral.

392. COSTA, Leonel Carlos da. Termo de ajustamento de conduta (TAC) e seus limites. Revista Jus Navigandi, Teresina, ano 19, n. 4140, 1 nov. 2014. Disponível em: <https://jus.com.br/artigos/30469>. Acesso em: 8 mar. 2016.

393. Idem

394. http://www.mazzilli.com.br/pages/artigos/evolcac.pdf 
"Natureza jurídica - O compromisso de ajustamento de conduta não tem natureza contratual, pois os órgãos públicos que o tomam não têm poder de disposição. Assim, não podem ser considerados uma verdadeira e própria transação, porque a transação importa poder de disponibilidade, e os órgãos públicos legitimados à ação civil pública ou coletiva, posto tenham disponibilidade do conteúdo processual da lide (como de resto é comum aos legitimados de ofício, como substitutos processuais que são), não detêm disponibilidade sobre o próprio direito material controvertido. Nesse sentido, o art. 841 do Código Civil corretamente dispóe que "só quanto a direitos patrimoniais de caráter privado se permite a transação".

Assim, o compromisso de ajustamento de conduta é antes um ato administrativo negocial (negócio jurídico de Direito Público), que consubstancia uma declaração de vontade do Poder Público coincidente com a do particular (o causador do dano, que concorda em adequar sua conduta às exigências da lei).

Assim, não podem os órgãos públicos legitimados dispensar direitos ou obrigações, nem renunciar a direitos, mas devem limitar-se a tomar, do causador do dano, obrigação de fazer ou não fazer (ou seja, a obrigação de que este torne sua conduta adequada às exigências da lei). Podem tais compromissos conter obrigaçóes pecuniárias, mas, dados os contornos que a lei lhes deu, não devem ser estas o objeto principal do compromisso, mas sim devem ter caráter de sanção em caso de descumprimento da obrigação de comportamento assumida." ${ }^{395}$

Logo, é evidente que a natureza jurídica dos TACs não coaduna com o direito eleitoral. O Tribunal Superior Eleitoral já sepultou a possibilidade de utilização dos TACs eleitorais. Vejamos.

Representação eleitoral. Descumprimento de termo de ajustamento de conduta.

1. A realização de termos de ajustamento de conduta previstos no art. $5^{\circ}, \S 6^{\circ}$, da Lei $n^{\circ}$ $7.347 / 85$ não é admitida para regular atos e comportamentos durante a campanha eleitoral, consoante dispóe o art. 105-A da Lei n $n^{\circ}$ 9.504/97.

2. A regulamentação da propaganda eleitoral não pode ser realizada por meio de ajuste de comportamento realizado por partidos, coligaçóes ou candidatos, ainda que na presença do Ministério Público e do Juiz Eleitoral, nos quais sejam estipuladas sançóes diferentes daquelas previstas na legislação eleitoral.

3. A pretensão de impor sanção que não tenha previsão legal e cuja destinação não respeite a prevista na legislação vigente é juridicamente impossivel.

Recurso especial parcialmente provido para extinguir, sem julgamento do mérito, a representação, desprovido o pedido de reconhecimento de litigância de má-fé.

(Recurso Especial Eleitoral no 32231, Acórdão de 08/05/2014, Relator(a) Min. HENRIQUE NEVES DA SILVA, Publicação: DJE - Diário de justiça eletrônico, Tomo 100, Data 30/05/2014, Página 60 ) 396 (grifo nosso)

395. idem

396. http://inter03.tse.jus.br/sadpPush/ExibirDadosProcessoJurisprudencia.do?nproc=915\&sgcla=RE\&comboTribunal $=\mathrm{mt} \&$ dataDecisao $=03 / 11 / 2009$ 
ELEIÇÕES 2004. Recurso especial eleitoral. Incompetência da Justiça Eleitoral para processar e julgar representação por descumprimento de termo de compromisso de ajustamento de conduta. Recurso ao qual se nega provimento.

(Recurso Especial Eleitoral n² 28478, Acórdão de 01/03/2011, Relator(a) Min. CÁRMEN LÚCIA ANTUNES ROCHA, Publicação: DJE - Diário da Justiça Eletrônico, Data 05/05/2011, Página 44 RJTSE - Revista de jurisprudência do TSE, Volume 22, Tomo 2, Data 01/03/2011, Página 54$)^{397}$ (grifo nosso)

Os tribunais regionais seguem a jurisprudência do TSE.

RECURSO ELEITORAL. EXECUÇÃO FIRMADA EM TERMO DE AJUTAMENTO DE CONDUTA. NULIDADE DO TÍTULO. EXTINÇÃO DO PROCESSO DE EXECUÇÃO. IMPROVIMENTO.- É nulo para todos os efeitos o Termo de Ajustamento de Conduta, firmado entre coligações e referendado pelo Ministério Público Eleitoral, que vise restringir direitos relativos à realização de propaganda eleitoral cominando pena de multa pelo descumprimento.

(Prestação de Contas no 915, Acórdão no 18566 de 03/11/2009, Relator(a) CÉSAR AUGUSTO BEARSI, Publicação: DEJE - Diário Eletrônico da Justiça Eleitoral, Tomo 532, Data 09/11/2009, Página 1-7 ) ${ }^{398}$ (grifo nosso)

A Lei n 9.504/97, a chamada Lei das Eleições e as Resoluções editadas pelo Tribunal Superior Eleitoral a cada eleição são suficientes para coibir qualquer irregularidade, ilegalidade e o abuso nas campanhas eleitorais. Não é necessária, em absoluto, a presença deste instrumento coercitivo denominado Termo de Ajustamento de Conduta Eleitoral para dar melhor ordem às campanhas.

Uma vez que a origem dos TACs é a Lei no 7.347/85 - que disciplina a ação civil pública - é de se ressaltar a expressa proibição dos TACs à luz do art. 105-A da Lei no 9.504/97, incluído pela Lei no $12.034 / 09$, verbis:

Art. 105-A. Em matéria eleitoral, não são aplicáveis os procedimentos previstos na Lei no 7.347, de 24 de julho de 1985.399

A presença dos TACs Eleitorais passou a ser um fator inibidor das manifestações políticas por parte dos candidatos, coligações, partidos, cabos eleitorais, simpatizantes e pelo eleitor. A argumentação de que a população não suportava mais as práticas de propaganda eleitorais não legitima o nascimento de um instrumento sem previsão legal eleitoral e coercitivo.

Se houver necessidade de se adequarem os comportamentos de propaganda eleitoral, deverá se realizar por meio de processo legislativo, modificando a Lei das Eleiçóes. Jamais um termo de ajustamento poderá calar a propaganda eleitoral garantida em lei vigente.

397. http://inter03.tse.jus.br/sadpPush/ExibirDadosProcessoJurisprudencia.do?nproc=284788sgcla=RE SPE_\&comboTribunal $=$ tse $\&$ dataDecisao $=01 / 03 / 2011$

398.http://inter03.tse.jus.br/sadpPush/ExibirDadosProcessoJurisprudencia.do?nproc=915\&sgcla=RE\&c omboTribunal $=\operatorname{mt} \&$ dataDecisao $=03 / 11 / 2009$

399. http://www.planalto.gov.br/ccivil_03/leis/L9504.htm 
$\mathrm{O}$ argumento de que se trata de um acordo não prevalece, tendo em vista que costumeiramente se vê a imposição, a coação na feitura de tais termos. O medo de retaliação, de perseguição, faz os candidatos concordarem em assinar os TACs. Um único candidato que se opõe a assinar o TAC sofrerá, sem dúvida, o peso de sua rebeldia.

Portanto, não resta dúvida da ilegalidade dos Termos de Ajustamento de Condutas Eleitorais, devendo ser rechaçados pelos candidatos, pelos partidos e pelas coligações, tendo em vista a afronta ao art. 105-A da Lei no 9.504/97, bem como pela dissonância em relação à jurisprudência do TSE. A legislação eleitoral em vigência é suficiente para que as campanhas eleitorais se desenvolvam na mais absoluta normalidade.

\section{Referências}

ALMEIDA, João Batista de. Aspectos controvertidos da ação civil pública. 1. ed. São Paulo: RT, 2001.

ALVIM, Frederico Franco. Manual de Direito Eleitoral. Belo Horizonte: Fórum, 2012.

DIDIER JUNIOR, Fredie. Curso de Direito Processual Civil. 4. ed. Salvador: JusPODIVM, 2009.

DINAMARCO, Cândido Rangel. Instituições de Direito Processual Civil. 4. Ed. São Paulo: Malheiros, 2005.

DINAMARCO, Pedro da Silva. Ação Civil Pública. SãoPaulo: Saraiva, 2001.

GOMES, José Jairo. Direito Eleitoral. 10. ed. Belo Horizonte: Del Rey, 2014.

ZILIO, Rodrigo López. Direito Eleitoral: noçõespreliminares, elegibilidade e inelegibilidade, açõeseleitorais, processo eleitoral. 3 ed. Porto Alegre: Verbo Jurídico, 2012. 
Recebido em: $12 / 03 / 2015$

Aceito em: 22/03/2016

\section{Como citar}

BLASZAK, José Luiz. A incoveniência dos TACs eleitorais. Ballot. Rio de Janeiro: UERJ. Volume 2 Número 1 Janeiro/Abril 2016. pp. 226-235.

Disponível em: [http://www.e-publicacoes.uerj.br/index.php/ballot]

\section{(ब) $\odot \odot$}

A Revista Ballot está licenciada sob uma licença Creative Commons Atribuição - Não Comercial - Compartilha Igual 3.0 Não Adaptada. 